\title{
José Carlos Libâneo: gênese e desenvolvimento de seu pensamento didático
}

\author{
Roberto Valdés Puentes ${ }^{1}$ \\ Andréa Maturano Longarezi
}

\begin{abstract}
RESUMO
$\mathrm{O}$ artigo tem como objetivo estabelecer e abordar os principais momentos no processo de gênese e desenvolvimento do pensamento didático de J. C. Libâneo (1945- ), a partir da adaptação da metodologia construtivointerpretativa para análise de documentos bibliográficos. O autor é responsável por uma obra que extrapola os limites geográficos brasileiros dada a magnitude e profundidade teórica de suas principais teses. A gênese e o desenvolvimento desse pensamento podem ser localizados na conjuntura contraditória e de tensões ideológico-políticas que caracterizaram as décadas de 1970 e 1980, assinalada por um intenso movimento de democratização e transformação social. De um pensamento didático filosófico daí emergente, se sobressai, entre suas contribuições teóricas, uma aproximação com as teses psicológicas histórico-culturais, que tem seu marco no ano de 1991; intensificadas, a partir de 2002, pela análise dos princípios da Didática Desenvolvimental, do conteúdo da Atividade de Estudo e do método do abstrato ao concreto como forma de desenvolvimento do pensamento teórico, com foco nos aportes do sistema Elkonin-Davidov-Repkin, tomado, particularmente, pelas contribuições do grupo de Moscou e de V. V. Davidov.
\end{abstract}

PALAVRAS-CHAVE: José Carlos Libâneo. Pensamento didático. Didática desenvolvimental.

\footnotetext{
1 Doutor em Educação. Docente do Curso de Pedagogia e do Programa de Pós-Graduação em Educação da Universidade Federal de Uberlândia, Minas Gerais, Brasil. https://orcid.org/0000-0001-8936-9362. robertovaldespuentes@gmail.com.

${ }^{2}$ Doutora em Educação. Docente, vinculada à Faculdade de Educação, nos cursos de licenciatura e no Programa de Pós-Graduação em Educação da Universidade Federal de Uberlândia, Minas Gerais, Brasil. https://orcid.org/00000002-5651-9333. andrea.longarezi@gmail.com.
} 
José Carlos Libâneo: genesis and evolution of his didactic views

\begin{abstract}
The present paper analyses the didactic views of J. C. Libâneo (1945- ), whose work goes beyond Brazilian geographical boundaries because of the theoretical value and depth of its main theses. The genesis and evolution of his views are located in a contradictory context of politicalideological strains, during 1970's and 1980's, a period marked by intense democratization and social transformation movement. This context made possible the emergence of a philosophical didactic view, from which the closeness to the historical-cultural psychological theses stands out, among other theoretical contributions. The aforementioned closeness began in 1991 and intensifies from 2002 due to the analyses of Developmental Learning principles, of Learning Activity content and, of the method from abstract to concrete as the way of developing theoretical thinking. J. C Libâneo's analyses has been focused on Elkonin-DavidovRepkin system contributions, notably, from Moscow Group and V. V. Davidov.
\end{abstract}

KEY WORDS: José Carlos Libâneo. Didactic view. Developmental didactic.

\title{
Introdução
}

José Carlos Libâneo (1945- ) é reconhecido pela sua trajetória acadêmica, docente, investigativa e militante no campo da Didática, o que faz dele um dos intelectuais e educadores brasileiros e latino-americanos mais importantes da segunda metade do século XX e da primeira do século XXI. Sua humanidade se expressa nas várias facetas que marcam sua obra e sua atividade profissional, sempre com uma postura generosa e humilde: "Sou metaforicamente um retirante, um filho de pais analfabetos, vivi até os 7 anos na roça, na pobreza, ... o que consegui foi benevolência da vida..." (LIBÂNEO, 2020). 
Juntamente com os intelectuais e pesquisadores brasileiros da área, Demerval Saviani, Antonio Joaquim Severino, Cipriano Luckesi, Carlos R. J. Cury, entre outros, José Carlos Libâneo consolida um pensamento progressista de educação, com forte influência de filósofos marxistas europeus e latino-americanos, tais como Karl Marx, Frederico Engels, Antonio Gramsci, David P. Ausubel, Georges Snyders, Bogdan Suchodolski, Adolfo S. Vázquez, Mario Manacorda e Bernard Charlot.

A gênese e o desenvolvimento do pensamento de J. C. Libâneo podem ser localizados na conjuntura contraditória e de tensões ideológico-políticas que caracterizaram as décadas de 1970 e 1980, assinalada por um intenso movimento de democratização e transformação social. Sua trajetória acadêmica é marcada por uma postura crítica, de luta contra a desigualdade social, com seu caráter propositivo de transformação pela via da educação escolar.

A atividade intelectual de J. C. Libâneo se manifesta, ao longo de quase cinquenta anos, em uma vasta e sólida produção na área ${ }^{3}$, de reconhecida expressividade política e acadêmica. A produção científica do autor possibilita a identificação de alguns aspectos que se constituem, por sua natureza sistêmica e transversal, em unidades nucleares de seu pensamento: 1. a defesa da democratização da sociedade; 2. a finalidade sócio-política da educação e da escola pública como mediadoras do processo de democratização; 3. a ênfase no conteúdo curricular da escola como componente fundamental dessa mediação; e 4. a aprendizagem desses conteúdos como elemento capital para a desalienação do homem, condição sine qua non para a formação e o desenvolvimento de uma sociedade mais igualitária.

O nível atingido pelo pensamento teórico e metodológico do autor, no campo didático, evidencia mudanças concernentes, especificamente, à sua

\footnotetext{
${ }^{3}$ Dentre as obras mais relevantes, podem ser mencionados os livros Democratização da escola pública: pedagogia crítico social dos conteúdos (1985 [1996]), Didática (1990[2002]), Organização e gestão da escola (2000a), Organização e gestão da escola: teoria e prática (2000b), Pedagogia e pedagogos, para quê? (2001a), Adeus professor, adeus professora? (2001b) etc..
} 
concepção sobre o conteúdo escolar e às formas de sua aprendizagem, o que nos leva à análise de sua gênese e desenvolvimento, finalidade do presente artigo. Estudos sobre a obra do autor no período de 1976 a 2020 (LONGAREZI, PUENTES, 2020), permitiu o estabelecimento de três etapas. A primeira se estende de 1976 a 1990, denominada Pensamento didático marxista numa perspectiva filosófica; a segunda de 1991 a 2001, compreendida como Pensamento didático marxista histórico-cultural e; a terceira, de 2002 a 2020, chamada de Pensamento didático marxista desenvolvimental ${ }^{4}$.

No seio dessa configuração, tomamos como ponto de referência o pensamento atual do autor marcado pela perspectiva desenvolvimental da didática, a partir da qual se procuraram as relações essenciais desse pensamento de modo a apreender os principais momentos do processo de gênese e desenvolvimento, com base na metodologia construtivointerpretativa adaptada para a análise de documentos bibliográficos.

\section{O pensamento didático na perspectiva desenvolvimental}

A Didática Desenvolvimental emerge na ex-União Soviética, na segunda metade da década de 1950, quando vários grupos de didatas, psicólogos, filólogos, fisiólogos e filósofos foram desenvolvendo experimentos em escolas pilotos dos anos inicias do nível fundamental, tendo em vista comprovar a tese vigoskiana sobre o papel do ensino e da aprendizagem no desenvolvimento psíquico (cf. PUENTES; LONGAREZI, 2017a; 2017b; 2018; LONGAREZI, 2017; LONGAREZI; DIAS DA SILVA; 2018; REVYAKINA;

\footnotetext{
4 "Essas etapas estão caracterizadas pela forte influência das teses marxistas sobre democracia, educação, escola, ensino, aprendizagem etc.. Contudo, na primeira delas, a abordagem do campo da Didática é efetuada por um viés mais filosófico, sobretudo, a partir das teses produzidas fora da ex-União Soviética, especialmente, por autores que viveram e escreveram no contexto de sociedades capitalistas, entre eles, K. Marx, F. Engels, G. Snyders, A. Gramsci, D. P. Ausubel, M. Manacorda, A. Vázquez e B. Charlot; na segunda, observa-se uma aproximação inicial a referenciais teóricos com fundamentos psicológicos, particularmente representados por autores do período soviético, tais como L. S. Vigotski e A. N. Leontiev; e na terceira já tem demarcada uma abordagem desenvolvimental da Didática, com base nos psicólogos e didatas soviéticos, representados não somente por L. S. Vigotski e A. N. Leontiev, mas também por S. L. Rubinstein, D. B. Elkonin, P. Ya. Galperin, V. V. Davidov etc.; além de autores europeus seguidores dessa perspectiva, tais como, o finlandês Yrjö Angström (2002), os dinamarqueses Seth Chaiklin (2001) e Mariane Hedegaard (2002), entre outros." (LONGAREZI; PUENTES, 2020, p. 4).
} 
LOBANOV; KULIKOV, 2017). Essa didática se constitui a partir da Teoria Desenvolvimental com base no pressuposto de que só adequadas condições de organização da aprendizagem garantem o desenvolvimento.

Entretanto, há de se destacar que a Didática Desenvolvimental não se constitui em um modo único de organização dos processos pedagógicos (PUENTES, 2019a; LONGAREZI, 2019a; 2019b; 2019d; LONGAREZI; SILVA, 2018). As especificidades didáticas desenham modos particulares de realização desse processo, gerando com isso a emergência de diferentes sistemas, entre os quais se destacam os sistemas Elkonin-Davidov-Repkin ${ }^{5}$, Galperin-Tazina e Zankov. A perspectiva mais conhecida no ocidente é a desenvolvida pelos vários grupos que trabalharam na edificação do sistema didático Elkonin-Davidov-Repkin (PUENTES, 2017; 2019b; PUENTES; AMORIM; CARDOSO, 2017; PUENTES; LONGAREZI, 2019; LONGAREZI, 2019a; 2019c; 2019d), especialmente, pela Teoria da Atividade de Estudo e as várias teorias auxiliares a ela relacionadas (cf. PUENTES; LONGAREZI, 2019; PUENTES, 2019c). V. V. Davidov, depois de D. B. Elkonin, pode ser considerado o representante mais importante desse sistema e o teórico mais conhecido fora da ex-união soviética.

Foi justamente V. V. Davidov quem defendeu, com base em E.V. Iliénkov (BORMEY; LEÓN; RODRÍGUEZ, 2019), que o papel da escola é o de ensinar a pensar teoricamente. J. C. Libâneo encontra aí respaldo para a tese que defende desde o início de sua carreira de que a apropriação do conteúdo escolar é fundamental para o processo de escolarização do estudante. Seu pensamento didático se caracteriza pelo nível de coerência que atingem os aspectos epistemológicos, teóricos e metodológicos, a partir da integração que se dá entre suas teses filosóficas materialista-dialéticas, seus pressupostos psicológicos histórico-culturais e sua pedagogia marxista, com a emergência de ideias que o orientam no sentido de uma teoria desenvolvimental da didática.

\footnotetext{
${ }^{5}$ Os autores deste capítulo empregam a mesma denominação que se usava e, ainda se usa, na maior parte das repúblicas ex-soviéticas onde esse sistema foi implementado (parte da Rússia, Ucrânia, Letônia, Lituânia, BieloRússia etc.).
} 
A obra do autor revela uma enorme contribuição para o avanço do pensamento pedagógico no Brasil, o que conduz suas energias para a dimensão didática do pensamento marxista, sem abrir mão dos pressupostos iniciais que sustentam sua ideologia e militância: a democratização social, a função da escola nesse processo, o conteúdo curricular na escola e o desenvolvimento como finalidade da educação.

O avanço do pensamento de J. C. Libâneo está marcado pelo encontro com as teses da Didática Desenvolvimental davidoviana ${ }^{6}$, atingindo sua máxima expressão com a concretização da unidade ensino-aprendizagemdesenvolvimento. Fica aqui explicita a defesa de que esse é um importante princípio na orientação didática desenvolvimental do autor, assim como a unidade da atividade do professor e dos alunos, com foco na valorização do sujeito, da sua aprendizagem e de seu desenvolvimento (LIBÂNEO; FREITAS, 2013).

Nota-se que o conteúdo, objeto da maior relevância na obra de J. C. Libâneo, sobre alterações. O que, inicialmente, denomina de "conteúdo cultural universal" comum que os alunos das escolas da elite têm acesso, passa para o "conhecimento científico" e culmina no "pensamento teórico", que é expresso pela unidade dos conceitos científicos e dos modos generalizados de ações. De acordo com o autor, o domínio desse tipo de pensamento (teórico) precisa considerar três aspectos vitais no processo educativo: a zona de desenvolvimento proximal, a internalização e o papel da cultura (conhecimento sistematizado no desenvolvimento mental dos alunos) (LIBÂNEO, 2011).

\footnotetext{
${ }^{6}$ Ainda quando em suas obras mencione outros didatas que marcam abordagens desenvolvimentais distintas, tal como P. Ya. Galperin, em sua Teoria da Formação das Ações Mentais e Conceitos por Etapas, fica marcada a influência do pensamento de V. V. Davidov, tal como pode se observar nesta e em muitas outras passagens do próprio autor: "O ensino desenvolvimental, tal como propôs Davidov, mantém a premissa básica da teoria históricocultural segundo a qual a educação e o ensino são formas universais e necessárias do desenvolvimento humano, em cujo processo estão interligados os fatores socioculturais e a atividade interna dos indivíduos. Mas este pesquisador ampliou consideravelmente essa premissa ao aprofundar a caracterização e a compreensão da atividade de aprendizagem com base na teoria da atividade de Leontiev." (LIBÂNEO; FREITAS, 2007, destaque dos autores).
} 
Nutrido dos pressupostos teóricos de L. S. Vigotski7, Libâneo (2004a, p.14) defende que "[...] a aprendizagem e o ensino são formas universais de desenvolvimento mental.”. A importância que atribui ao desenvolvimento do pensamento teórico (conhecimentos sistematizados), como conteúdo e finalidade da atividade pedagógica, pode ser vista quando afirma que o ensino permite

[...] a apropriação da cultura e o desenvolvimento do pensamento, dois processos articulados entre si, formando uma unidade. Podemos expressar essa ideia de duas maneiras: a) enquanto o aluno forma conceitos científicos, incorpora processos de pensamento e vice-versa; b) enquanto forma o pensamento teórico, desenvolve ações mentais, mediante a solução de problemas que suscitam a atividade mental do aluno. Com isso, o aluno assimila o conhecimento teórico e as capacidades e habilidades relacionadas a esse conhecimento. (LIBÂNEO, 2004a, p. 14, destaques dos autores).

Por essa perspectiva, o pensamento teórico se forma por um processo complexo de assimilação que se constitui no movimento de ascensão do abstrato ao concreto (método dedutivo). J. C. Libâneo, com base em V. V. Davidov, defende que só esse método permite desenvolver o pensamento teórico, porque garante “[...] uma relação principal geral que caracteriza o assunto e se descobre como essa relação aparece em muitos problemas específicos. Isto é, de uma relação geral subjacente ao assunto ou problema se deduzem mais relações particulares." (LIBÂNEO, 2004a, p. 17, destaque dos autores).

Do ponto de vista didático, o modo de assimilação dos conteúdos é, ao mesmo tempo, conteúdo do pensamento teórico. São as mediações cada vez

\footnotetext{
7 "Libâneo e Freitas (2007) enfatizam que Vygotsky também voltou suas pesquisas para temas como a origem e o desenvolvimento do psiquismo, processos intelectuais, emoções, consciência, atividade, linguagem, desenvolvimento humano, aprendizagem, formando assim a base teórica da psicologia histórico-cultural." (LONGAREZI, PEDRO; PERINI, 2011, p. 390).
} 
mais abstratas que promovem modos generalizados de pensamento. Nesse sentido, a qualidade do pensamento teórico é dada pela mediação do conhecimento científico e pelos modos generalizados ${ }^{8}$ de tratar esses conceitos. Ancorado nessa perspectiva davidoviana, J. C. Libâneo compreende que o desenvolvimento do “[...] pensamento teórico é o processo pelo qual se revela a essência e desenvolvimento dos objetos de conhecimento, e com isso a aquisição de métodos e estratégias cognoscitivas gerais de cada ciência, em função de analisar e resolver problemas cotidianos e profissionais." (LIBÂNEO, 2004a, p. 19).

$\mathrm{Na}$ Didática Desenvolvimental, com base na teoria da atividade principal de A. N. Leontiev, o estudo é a atividade guia dos processos de assimilação que conduzem à aprendizagem desenvolvimental na idade escolar (dos 6/7 anos - 11/12 anos). Com base nessa concepção, D. B. Elkonin, V. V. Davidov, V. V. Repkin, entre outros, desenvolveram uma Teoria da Atividade de Estudo, entendida como aquele tipo específico de atividade humana que transforma a realidade objeto de análise e, enquanto ato de transformação, autotransforma o sujeito dela. Essa atividade se caracteriza por uma função específica, um conteúdo, uma estrutura e um processo formativo (DAVIDOV; MÁRKOVA, 1987; REPKIN; REPKINA, 2019) e se distingui por seu caráter colaborativo já que nela estão implicados de maneira ativa alunos e professor.

J. C. Libâneo reconhece a importância que a Atividade de Estudo (LIBÂNEO, 2018; LIBÂNEO; FREITAS, 2013; 2018; FREITAS; LIBÂNEO, 2018) ${ }^{9}$ ocupa no interior da Didática Desenvolvimental, mesmo quando inicialmente a identifica como Atividade de Aprendizagem ${ }^{10}$ (LIBÂNEO,

\footnotetext{
8 “[...] generalização teórica significa: analisar de maneira autônoma os dados da tarefa; separar neles as conexões essenciais; considerar cada tarefa como uma variante particular daquela que havia sido resolvida inicialmente por meios teóricos (1987, p. 154; 1988b, p. 30, 49).”(LIBÂNEO, 2004a, p. 17).

${ }^{9}$ Observa-se que, sobretudo a partir de 2007, a maior parte da produção intelectual de J. C. Libâneo sobre Didática Desenvolvimental acontece em parceria com Raquel Aparecida Marra da Madeira Freitas, docente do Programa de Pós-Graduação em Educação da PUC-Goiás. Por esse motivo, ainda quando o presente texto não procura analisar as influencias recíprocas entre ambos os autores, reconhece-se a participação ativa que a autora teve na formação e consolidação do pensamento didático de J. C. Libâneo.

${ }^{10}$ Nota-se que o termo Atividade de Aprendizagem é utilizado pelo autor, especialmente, quando faz uso da versão em inglês da obra de Davidov (1988).
} 
2004a,b; 2008b; LIBÂNEO; FREITAS, 2007) e/ou Atividade de Assimilação (LIBÂNEO, 2004b). Dá ênfase ao pensamento teórico como conteúdo dessa atividade, ao seu papel na formação dos conceitos científicos (em lugar dos empíricos), ao seu caráter social e coletivo, pela via da comunicação (material e espiritual) e da atividade conjunta; bem como à sua contribuição para a formação profissional docente (LIBÂNEO, 2004a, b; 2018; LIBÂNEO; FREITAS, 2007; 2013; 2018; FREITAS; LIBÂNEO, 2018).

No bojo dessa perspectiva epistemológica, teórica e didática, Libâneo (2008b) traz uma importante contribuição para a discussão da natureza e do sentido da Didática Geral e das Didáticas Específicas, com o olhar também para o contexto da formação profissional docente (LIBÂNEO, 2004b). Apoiado nos fundamentos psicológicos e didáticos da formação e desenvolvimento das qualidades psíquicas, bem como do próprio pensamento teórico, o autor defende que a apropriação da epistemologia da ciência é condição indispensável para a assimilação da própria ciência na forma de conteúdo curricular. Nesse sentido,

A organização pedagógico-didática dos conteúdos pressupõe a análise epistemológica, tanto no que se refere aos métodos do conhecimento quanto à análise do objeto da ciência ensinada e dos seus procedimentos investigativos. Isso nos leva a afirmar que não faz sentido uma didática separada da teoria do conhecimento, da psicologia do desenvolvimento e aprendizagem e, especialmente, das peculiaridades epistemológicas das disciplinas e dos seus métodos de investigação. (LIBÂNEO, 2008b, p. 16).

O autor enfatiza a relação que deve existir entre o conteúdo escolar e o conteúdo científico, o qual procura garantir pela unidade que estabelece entre a episteme da Didática e a epistemologia da ciência. A esse respeito defende que "[...] o modo de lidar pedagogicamente com algo, depende do modo de lidar epistemologicamente com algo, considerando as condições do aluno e o contexto sociocultural em que ele vive." (LIBÂNEO, 2008b, p. 13). 
Para J. C. Libâneo,

[...] ao aprender, o aluno se apropria do processo histórico real da gênese e do desenvolvimento do conteúdo e, assim, internaliza os métodos e estratégias cognitivas gerais da ciência ensinada (isto é, procedimentos mentais operatórios, a fim de analisar e resolver problemas e situações concretas da vida prática). (LIBÂNEO, 2011, p. 23-24).

Em se tratando do pensamento teórico como conteúdo curricular a que a escola deva se dedicar, compreende que esse processo ocorre mediante abstrações e generalizações substantivas, a partir das quais a aprendizagem teórica

[...] consiste em captar o princípio geral, as relações internas de um conteúdo, o desenvolvimento do conteúdo. É aprender a fazer abstrações para formar uma célula dos conceitos-chave, para fazer generalizações conceituais e aplicá-las a problemas específicos. (LIBÂNEO, 2008b, 14).

Quando traz essa discussão para o campo da formação de professores e do papel da didática nesse processo alerta que

[..] não basta o professor dominar o conteúdo, ele precisa conhecer, também, os processos investigativos da disciplina, as ações mentais, os procedimentos lógicos da disciplina, pois, na concepção atual da aprendizagem, aprender implica uma relação do aluno com os objetos do saber, muito próxima da relação que o cientista tem com seu saber. (LIBÂNEO, 2011, p.23).

Em textos mais recentes, Libâneo (LIBÂNEO; FREITAS, 2019) aborda com maior nível de profundidade os conceitos de abstração, generalização e conceitualização como procedimentos didáticos responsáveis 
pela formação do pensamento teórico. Apoia-se, para isso, nas teses de L. S. Vigotski e V. V. Davidov sobre o assunto. Além disso, elimina definitivamente qualquer vestígio de ensino transmissivo, bem como de aprendizagem construtivista baseado apenas no esforço próprio dos alunos. Aliás, explicita uma crítica aberta a essas duas concepções metodológicas por sua incapacidade de promover o desenvolvimento do pensamento teórico:

O ensino apenas pela exposição do conteúdo e de informações a serem reproduzidas pelos alunos, assim como a crença de que eles podem aprender por si mesmos com pouca interferência do professor, são duas estratégias ineficientes quando se trata de um ensino voltado para o desenvolvimento global dos alunos. No primeiro caso, é comum o professor transmitir o conteúdo da matéria sem prover os alunos dos meios cognitivos. [...] No segundo caso, a aprendizagem acontece acidentalmente conforme leis próprias do desenvolvimento espontâneo ou natural das capacidades dos alunos... (LIBÂNEO; FREITAS, 2019, p. 229, destaques dos autores).

De acordo com o autor, tanto uma como outra visão, não conseguem ir além dos limites do pensamento empírico porque a aprendizagem que conduz ao desenvolvimento do pensamento teórico e demais capacidades psíquicas só é possível em um tipo específico de atividade humana: a Atividade de Estudo (LIBÂNEO; FREITAS, 2019). Essa atividade demanda, sobretudo, a implicação do aluno, a assimilação, a comunicação, a colaboração, bem como a ação de planejamento e orientação do professor de situações-problemas que são elaboradas na zona de desenvolvimento próximo.

O foco do autor está na organização de processos de aprendizagem, com base em conteúdos que empoderam crianças, jovens e adultos das 
camadas mais pobres, pela via da desalienação, estimulando com isso a construção de uma sociedade mais justa e mais democrática. A qualificação do conteúdo (pensamento teórico) e a finalidade do processo educativo escolar em potencializar, ao máximo, o desenvolvimento humano são as marcas do pensamento atual de J. C. Libâneo. Para os propósitos do presente artigo e diante das assertivas apresentadas, cabe revelar as relações essenciais do pensamento didático desenvolvimental em sua gênese e desenvolvimento.

\section{Pensamento didático na perspectiva histórico-cultural}

Uma análise do pensamento do autor, a partir de suas pesquisas educacionais, revela a influência dos pressupostos histórico-culturais em relação à aprendizagem e ao desenvolvimento dos estudantes em uma perspectiva psicológica, mas ausente de referenciais no campo da didática. Nesse momento, seu esforço foi o de "[...] traduzir pressupostos pedagógicos para uma didática crítico-social [...] não dispunha, então de uma literatura de orientação marxista que tratasse de temas especificamente didáticos. (LIBÂNEO, 2006, p. 49).

Observa-se uma preocupação nova em relação à consideração da idade, do desenvolvimento mental e das características de aprendizagem dos estudantes, quando o autor apresenta, em seu estudo sobre as tendências pedagógicas no Brasil, a crítica à Pedagogia Libertadora:

Em relação a sua aplicação nas escolas públicas (se refere a Pedagogia Libertadora), especialmente no ensino de $1^{\circ}$ Grau, os representantes dessa tendência não chegaram a formular uma orientação pedagógico-didática especificamente escolar, compatível $\underline{\text { com a idade, }} \underline{\text { o desenvolvimento mental e as características de }}$ aprendizagem de crianças e jovens (LIBÂNEO, 1991 [2008a], p. 69-70; acréscimo e destaque dos autores). 
A partir desse momento emerge, no pensamento do autor, uma forte inclinação em favor de uma perspectiva que trata de forma interdependente os processos de ensino, aprendizagem e desenvolvimento. Esse posicionamento se dá por intermédio da tese de que "as formas de ensinar dependem das formas de aprender" (LIBÂNEO, 1991[2008a]), dado que "a condução do processo de ensino requer uma compreensão clara e segura do processo de aprendizagem: em que consiste, como as pessoas aprendem, quais as condições externas e internas que o influenciam" (LIBÂNEO, 1991[2008a], p. 81).

Sob a base da psicologia histórico-cultural que marca o desenvolvimento do pensamento do autor, observa-se a valorização que no papel da Didática assumem as leis e os princípios gerais do ensino, da aprendizagem e do desenvolvimento das capacidades cognitivas e da personalidade, com base em clássicos dessa psicologia, tais como Vigotsky (1984) e Leontiev (1980). Segundo Libâneo (1991[2008a], p. 71, destaques dos autores), a Didática

...é a disciplina que estuda o processo de ensino tomado em seu conjunto [...] investiga as leis e os princípios gerais do ensino e da aprendizagem [...] independência de pensamento [...] a educação de traços da personalidade (como caráter, vontade, sentimentos), [...] a aquisição dos conhecimentos e desenvolvimento das capacidades.

Contudo, essa interdependência se observa com muito mais nitidez entre o ensino e a aprendizagem do que desses componentes com o desenvolvimento. Sendo assim, realça-se a unidade ensino-aprendizagem (LIBÂNEO, 1991[2008a]), ainda quando se destaque o desenvolvimento como componente importante do processo educativo. J. C. Libâneo chegou a considerar essa relação como foco especial de interesse da Didática. 
Estes dois termos - ensino e aprendizagem - aparecem tantas vezes junto na nossa fala cotidiana que quase não chama a atenção o fato de que [se] destaque tanto o ensino quanto a aprendizagem, um complementando outro. Quem tem familiaridade com as tendências pedagógicas sabe que elas se diferenciam bastante quanto ao peso que dão a um ou outro polo do ato didático. Minha posição sustenta a ideia de que o ensino é uma atividade intencional destinada a assegurar a aprendizagem dos alunos. Mas, não vejo aí uma relação linear de causa-efeito, o professor ensina, o aluno aprende. Vejo uma relação dinâmica na qual o professor dirige o processo de ensinar de modo que, com a parceria dele, o próprio aluno vai ampliando suas capacidades cognoscitivas e realiza, ele mesmo, as tarefas de aprendizagem [...] É importante frisar, então, que a Didática, como teoria do processo de ensino, investiga os nexos entre o ensino e a aprendizagem, entre o trabalho docente e o trabalho discente, entre a direção do professor e a auto formação do aluno, relações essas que indicam os elementos comuns do ensino das diferentes matérias (LIBÂNEO, 1990[2002], p. 10, acréscimos e destaques dos autores).

Observa-se, além da busca incansável pela necessária unidade entre ensino, aprendizagem e desenvolvimento, preocupação explícita por duas dimensões importantes do desenvolvimento humano: o pensamento e a personalidade.

A aquisição de conhecimentos e habilidades implica a educação de traços da personalidade (como caráter, vontade, sentimentos); estes, por sua vez, influenciam na disposição dos alunos para o estudo e para a aquisição dos conhecimentos e desenvolvimento de capacidades (LIBÂNEO, 1991[2008a], p. 71, destaques dos autores).

Contudo, a personalidade não foi objeto de aprofundamento teórico ressaltando o caráter cognitivo do processo de ensino-aprendizagem porque 
tem como finalidade o "domínio dos conhecimentos e desenvolvimento das capacidades cognitivas" (LIBÂNEO, 1991[2008a], p. 79), bem como porque considera a aprendizagem como "uma relação cognitiva entre o sujeito e os objetos de conhecimento" (LIBÂNEO, 1991[2008a], p. 83-84). O pensamento, por sua vez, não recebeu maiores especificações ficando em aberto.

Há uma intensificação das posições do autor em relação à centralidade do conteúdo de ensino no processo didático-pedagógico, que amplia sua compreensão em relação ao conteúdo, quando o define como o "conjunto dos elementos, propriedades, características próprias de um objeto, de um processo, de um problema e que interagem entre si” (LIBÂNEO, 1991[2002], p. 82). Por esse novo entendimento incorpora, junto com os conhecimentos, a formação das habilidades, hábitos, atitudes e valores, como marco do reconhecimento de aspectos psicológicos históricoculturais em seu pensamento didático.

Nessa mesma linha teórica, os "conteúdos culturais universais" dão lugar aos "conteúdos científicos"; assim como o "desenvolvimento das capacidades e habilidades intelectuais, os métodos de estudo e hábitos de raciocínio" passam a ocupar lugar preponderante na sua concepção didática.

A Pedagogia Crítico-Social [...] postula para o ensino a tarefa de propiciar aos alunos o desenvolvimento de suas capacidades e habilidades intelectuais, mediante $\underline{\text { a transmissão e assimilação }}$ ativa dos conteúdos escolares articulando, no mesmo processo, a aquisição de noções sistematizadas e as qualidades individuais dos alunos que lhes possibilitem a auto atividade e a busca independente e criativa das noções [...] o domínio de conteúdos $\underline{\text { científicos, }}$ os métodos de estudo e habilidades e hábitos de raciocínio, de modo a irem formando a consciência crítica face às realidades sociais... (LIBÂNEO, 1991[2008a], p. 70-71, destaques dos autores). 
Além de estabelecer os componentes básicos do conteúdo (conhecimentos, habilidades, hábitos e valores), especifica os elementos que integram cada um deles (LIBÂNEO, 1991[2008a]): 1. os conhecimentos sistematizados (integrados por fatos, conceitos, princípios, métodos de conhecimento etc.); 2. as habilidades e hábitos intelectuais e sensóriomotores (compostos pela capacidade de observar um fato e extrair conclusões, destacar propriedades e relações das coisas, dominar procedimentos para resolver exercícios, escrever e ler, usar adequadamente os sentidos, manipular objetos e instrumentos etc.); e 3. as atitudes e valores (compreendidos pela perseverança e responsabilidade no estudo, pelo modo científico de resolver problemas humanos, pelo senso crítico frente aos objetos de estudo e à realidade, pelo espírito de camaradagem e solidariedade, convicções, valores humanos e sociais, pelo interesse no conhecimento, pelos modos de convivência social etc.).

Do ponto de vista metodológico, o papel do professor se firma pela atividade de transmissão (conforme transcrito na passagem anterior), porém, incluindo agora aspectos próprios da psicologia histórico-cultural, evidentes quando defende (no mesmo excerto):

[...] a aquisição de noções sistematizadas e as qualidades individuais dos alunos que lhes possibilitem a auto atividade e a busca independente e criativa das noções [...] o domínio de conteúdos científicos, os métodos de estudo e habilidades e hábitos de raciocínio, de modo a irem formando a consciência crítica face às realidades sociais... (LIBÂNEO, 1991[2008a], p. 70-71, destaques dos autores).

Os métodos de ensino que apresenta e descreve (LIBÂNEO, 1991 [2008a], p. 149-176), emergem das teses que estabelecem autores procedentes de países socialistas europeus (DANILOV; SKATKIN, 1978; DANILOV, 1978; KLINGBERG, 1978), com foco na exposição pelo professor, 
no trabalho independente, na elaboração conjunta e no trabalho em grupo (LIBÂNEO, 1991 [2008a], p. 149-176).

No momento que antecede o pensamento didático desenvolvimental de J. C. Libâneo, observa-se o confronto sistemático entre a nova tese da assimilação ativa ou apropriação de conhecimentos e habilidades, como resultado de um "processo de percepção, compreensão, reflexão e aplicação que se desenvolve com os meios intelectuais, motivacionais e atitudinais do próprio aluno, sobre a direção e orientação do processor" (LIBÂNEO, 1991[2008a], p. 83) e a antiga tese da organização dos “[...] conteúdos para sua transmissão, de forma que os alunos possam ter uma relação subjetiva com eles [...] Transmitir a matéria, nesse sentido, é traduzir didaticamente a matéria para alunos determinados...” (LIBÂNEO, 1991[2008a], p. 89-90).

Aliás, o autor critica numerosas vezes o processo de aprendizagem que se baseia na transmissão e defende o novo papel que atribui ao professor e aos alunos ao afirmar, entre outras coisas, que "a relação entre ensino e aprendizagem não é mecânica, não é uma simples transmissão do professor que ensina para um aluno que aprende", pelo "contrário, é uma relação recíproca na qual se destacam o papel dirigente do professor e a atividade do aluno" (LIBÂNEO, 1991[2008a], p. 90, destaque dos autores). Somente quando o nível do pensamento didático do autor atinge sua dimensão desenvolvimental é que ficam melhor definidos os conceitos de direção e orientação do trabalho do professor e o conceito marxista de atividade, especificamente, o de Atividade de Estudo.

Por fim, ressaltasse que a tese do autor sobre a subordinação dos métodos ao conteúdo de cada matéria foi validada (LIBÂNEO, 1991[2008a], 1991[2002]). De acordo com Libâneo (1991[2002], p. 84), o método de ensino se determina

[...] pela relação conteúdo-forma no objeto de conhecimento, ou seja, a utilização de um determinado método de ensino depende da matéria e do assunto a tratar, de modo que o método de ensino 
reflete a lógica da ciência que serve de base à matéria de ensino. Podemos dizer, assim, que o conteúdo determina o método (destaque dos autores).

Além disso, acrescenta mais um elemento nessa relação ao afirmar que os métodos se subordinam, também, às características de aprendizagem dos alunos, isto é, aos "conhecimentos e experiências que trazem, suas expectativas, seu nível de preparo para enfrentar a matéria etc." (LIBÂNEO, 1991[2008a], p. 92), com o que se garante o cumprimento do princípio da unidade ensino-aprendizagem.

\section{Pensamento didático na perspectiva filosófica}

A formação do ideário de J. C. Libâneo é marcada pela confluência de perspectivas que emergiram, nas décadas de 1970 a 1990, em diálogo com o ideário pedagógico, filosófico, sociológico e didático mais contemporâneo na América Latina e no mundo. Em princípio, seu pensamento oscila entre abordagens distintas, quando tenta conciliar, como era comum no pensamento pedagógico brasileiro e latino-americano, as ideias fundamentais do marxismo, com concepções de aprendizagem ancoradas em abordagens psicológicas de fundamentação cognitivista, significativa e/ou cibernética, assim como com uma perspectiva pedagógico-didática que, em sua essência, se baseia na transmissão do conteúdo, própria de uma pedagogia tradicional.

Cabe destacar que no final da década de 1970 emerge um importante movimento, denominado Pedagogia Crítico-social dos Conteúdos, que consolida essa perspectiva marxista no Brasil, em oposição à influência da Escola Nova e de outras teorias cognitivas, comportamentais, críticoreprodutivista e da desescolarização, acentuando a relevância dos conteúdos no confronto com as realidades sociais. Essa perspectiva se destaca pela importância que atribui à transmissão dos conteúdos, ressaltando, enquanto 
método, a condição ativa do aluno na atividade pedagógica. José Carlos Libâneo se encontra entre os principais representantes desse movimento concomitantemente a Demerval Saviani.

A concepção predominante nesse período, da qual o autor é um de seus principais protagonistas, coloca a educação escolar como um processo que integra a atividade pedagógica ao "[...] conjunto das mediações que compõem a totalidade das práticas sociais." (LIBANEO, 1986, p. 8). Em face disso, para se definir o tipo de educação que se pretendia, balizava-se pela orientação ideológica do tipo de sociedade que se procurava formar. Esse era um ponto importante e orientador das concepções pedagógicas assumidas à época.

Ao abordar o papel da escola no interior da Pedagogia Crítico-Social dos Conteúdos, o autor assume um posicionamento estritamente marxista que se baseia, em essência, nas teses principais sobre a função das instituições escolares no processo de democratização social a partir da compreensão das condições existentes; também compartilhadas, em âmbito nacional, por Saviani, Cury, Mello, Rosenberg e Brandão, e internacional por B. Charlot, B. Suchodolski, G. Snyders e M. Manacorda.

Os pressupostos de aprendizagem que sustentam o pensamento do autor, mesmo quando apresentam teses que o conectam com o pensamento marxista mais avançado, apoiam-se também em aspectos de natureza psicológica com características mais pragmáticas e idealistas, o que pode ser evidenciado quando defende que:

Por um esforço próprio, o aluno se reconhece nos conteúdos e modelos sociais apresentados pelo professor; assim, pode ampliar sua própria experiência. O conhecimento novo se apoia numa estrutura cognitiva já existente, ou o professor provê a estrutura de que o aluno ainda não dispõe. O grau de envolvimento na aprendizagem depende tanto da prontidão e disposição do aluno, quanto do professor e do contexto da sala de aula. 
Aprender, dentro da visão da pedagogia dos conteúdos, é desenvolver a capacidade de processar informações e lidar com os estímulos do ambiente, organizando os dados disponíveis da experiência. Em consequência, admite-se o princípio da aprendizagem significativa que supõe, como passo inicial, verificar aquilo que o aluno já sabe. O professor precisa saber (compreender) o que os alunos dizem ou fazem, o aluno precisa compreender o que o professor procura dizer-lhes. A transferência da aprendizagem se dá a partir do momento da síntese, isto é, quando o aluno supera sua visão parcial e confusa e adquire uma visão mais clara e unificadora (LIBÂNEO, 1985, p. 42, destaques dos autores).

Notam-se afirmações procedentes de concepções teóricas da psicologia cognitivista, do enfoque da aprendizagem significativa e da teoria cibernética, junto com uma compreensão materialista histórico-dialética da aprendizagem. Mesmo assim, elabora uma crítica à psicologia corrente na época com referencial marxista que se apoiava no conhecimento inicial do pensamento de A. N. Leontiev e S. L. Rubinstein (LIBÂNEO, 2020).

No concernente aos aspectos didático-pedagógicos relacionados ao conteúdo ${ }^{11}$, aos métodos e à relação professor-aluno, o pensamento didático expresso na obra de J. C. Libâneo, nesse período, defende o acesso das camadas populares ao conhecimento que recebem os alunos das camadas mais ricas. O autor considera-os como "conteúdos culturais universais que se constituíram em domínios de conhecimento relativamente autônomos, incorporados pela humanidade" (LIBÂNEO, 1985. p. 39, destaques dos autores). Ainda quando não discrimina um tipo de conteúdo diferente do estabelecido no currículo escolar que seja passível de promover superações reais nos processos psíquico-sociais dos estudantes, supera uma perspectiva

\footnotetext{
${ }^{11}$ No que diz respeito, particularmente, à ênfase nos conteúdos J. C. Libâneo reconhece a forte influência que seu pensamento teve, sob esse aspecto em particular, do livro Pedagogia Progressista, de G. Snyders. A partir dessa obra J. C. Libâneo assume, desde então e até o presente momento que é "na relação com os conteúdos que se encontra o destino das pedagogias" (LIBÂNEO, 2020).
} 
tradicional pelo fato de colocar os conteúdos na sua relação com as realidades sociais. ${ }^{12}$

J. C. Libâneo defende a articulação dos conteúdos com a experiência social concreta dos alunos, tomando o saber enquanto manifestação da cultura, como "[...] produtos da ação transformadora do homem sobre a natureza e as relações sociais.” (LIBÂNEO, 1986, p. 6). Na arquitetura da Pedagogia Crítico-social dos Conteúdos, como tendência pedagógica defendida pelo pensamento didático filosófico libaneano,

Os conteúdos escolares não são mais que expressões, para fins pedagógicos, do conjunto de bens culturais elaborados, reelaborados e sistematizados no processo da prática históricosocial dos homens, tendo em vista a formação cultural. Englobam conceitos, ideias, leis, generalizações, bem como processos e habilidades cognitivas e de linguagem contidos nos programas, nos livros didáticos, nas aulas, nas leituras complementares, nos exercícios de fixação, nos trabalhos escritos, etc. Pode se afirmar que, em certa medida, os conteúdos implicam métodos e, estes, conteúdos. (LIBÂNEO, 1986, p. 10).

Considerando que a herança cultural era compreendida em permanente transformação, os conteúdos escolares, por sua vez, também eram vistos em construção, constituindo-se na relação em e/ou na relação com. Por isso, esses, “[...], desde sua gênese, contêm a dimensão críticosocial, evidenciando a relação conteúdos-métodos no processo de formação cultural.” (LIBÂNEO, 1986, p. 10).

\footnotetext{
12 Mesmo quando já no artigo Tendências pedagógicas na prática escolar, de 1982, percebemos essa relação entre os conteúdos e a realidade social e, portanto, a presença de um referencial marxista no pensamento educacional de J. C. Libâneo, ele mesmo afirma que foi em Didática e prática histórico-social (1984) onde tal referencial se expressou pela primeira vez e onde produziu uma frase que iria aparecer em textos posteriores e que mantém até hoje: articular os conteúdos escolares com a experiência social concreta dos alunos (LIBÂNEO, 2020). Nesse artigo em questão Libâneo (1985, p. 139-140) iria escrever: "Nesse caso, uma boa parte do campo da didática refere-se às mediações (assumidas pelo professor) pelas quais se promoverá o encontro entre o aluno com sua experiência social concreta e o saber escolar".
} 
Ainda assim, a ausência de um novo tipo de conteúdo na obra de J. C. Libâneo fica evidente no método geral de ensino que adota no início de seu pensamento, ao defender que o conhecimento é resultado de uma relação contínua e progressiva em que o aluno "[...] passa da experiência imediata e desorganizada ao conhecimento sistematizado." (LIBÂNEO, 1985, p. 40, destaque dos autores). Nessa perspectiva, compreende que a

[...] aula começa pela constatação da prática real, havendo, em seguida, a consciência dessa prática no sentido de referi-la aos termos do conteúdo proposto, na forma de um confronto entre a experiência e a explicação do professor. Vale dizer: vai-se da ação à compreensão e da compreensão à ação, até a síntese, o que não é outra coisa senão a unidade entre a teoria e a prática (LIBÂNEO, 1985, p. 41, destaques dos autores).

Essa visão marxista do processo de produção do conhecimento, compartilhada por boa parte dos representantes do pensamento pedagógico e filosófico progressista brasileiro da época, era também uma das teses fundamentais do pensamento de D. Saviani que deu sustentação à Pedagogia Histórico-Crítica, com as quais J. C. Libâneo se identificou; e que, quando analisada em sua essência, reflete o método indutivo que expressa o modo como os clássicos do marxismo compreendiam o processo peculiar pelo qual a humanidade produz o conhecimento científico, mas não, necessariamente, o modo como deva ser produzido o conhecimento escolar na sala de aula.

O método de ensino indutivo (ou de indução) tem sua gênese no pressuposto que, após considerar um número suficiente de casos particulares com base na experiência imediata, o estudante conclui uma verdade geral, na forma de conhecimento sistematizado. Esse método parte de dados particulares da experiência sensível, da observação, a partir da qual o conhecimento pode ser adquirido. $\mathrm{Na}$ sala de aula, a indução considera importante a enumeração de dados a partir da experiência em 
número suficiente que permita a passagem do particular para o geral, a ascensão do concreto ao abstrato (uma forma de elaboração superior). Contudo, o abstrato aqui não é considerado uma generalização de caráter substantivo ou essencial (que caracteriza um tipo de conhecimento científico).

Um aspecto extremamente importante na compreensão da relação conteúdos-método no pensamento pedagógico em destaque se dá pela primazia dos conteúdos que assumem um papel determinante na atividade pedagógica, sendo o método deles derivados.

São os conteúdos que mobilizam ou não a atividade do aluno, são eles que trazem ou não questões essenciais que tenham ou venham a ter significado vital. Tratar os métodos de ensino separada ou predominantemente em relação aos conteúdos (caso, por exemplo, de propostas pedagógicas que fazem do trabalho escolar apenas oportunidade de discussão ou livre expressão da experiência vivida no cotidiano), é uma atitude que leva à segregação, pois esvazia a importância dos conteúdos como requisito para a interpretação e organização da experiência. (LIBÂNEO, 1986, p. 10).

Entretanto, ainda quando o autor coloque uma relação de subordinação dos métodos aos conteúdos, não os secundariza, pois os concebe como fundamentais para a apropriação ativa dos conteúdos e nisso reside sua relação de dependência.

Do pondo de vista metodológico, o autor descreve como necessário

[...] um momento do processo didático corresponde à aproximação dos conteúdos da experiência vivida e dos conhecimentos já disponíveis, sistematizados ou não. Em seguida, procede-se à seleção e ordenação de conhecimentos, enriquecidos por novas observações por meio de atividades de reflexão, compreensão, análise, relações, etc. que permitam apreender a historicidade e 
relevância social dos conteúdos. Finalmente, chega-se às leis que explicam a realidade física e humana, integrando os conhecimentos em sínteses ampliadoras, enfim, consolidando o processo de aprendizagem. Portanto, nada parecido com simples memorizações, dogmatismos, ou absorção de conteúdos práticos. Evidentemente, que o procedimento didático esboçado não é linear; além disso, cada momento descrito contém uma infinidade de possibilidades didáticas que podem incluir desde o método de problemas e o trabalho em grupo, até aos chamados multimeios. (LIBÂNEO, 1986, p. 10-11).

Na perspectiva assumida pelo pensamento didático filosófico de J. C. Libâneo, a difusão indiscriminada da cultura a todos é o real papel da escola pela via da "[...] transmissão de conteúdos básicos do saber sistematizado contido nas matérias de estudo, por métodos de apropriação ativa e outros processos pedagógicos, como requisito para a ação prática humana no mundo do trabalho e da vida social.” (LIBÂNEO, 1986, p. 6, destaques dos autores). Destarte que os métodos e procedimentos são tomados como processo ativo do estudante com movimentos que culminam na apreensão das leis gerais que explicam a realidade física e humana, ampliadoras dos conhecimentos, para além de práticas de memorizações, mas que, todavia, oscilam no pensamento do autor com práticas pedagógicas ainda pautadas na transmissão de conteúdos; revelador de certos antagonismos determinados pelo choque entre o que se compreende por transmitir e o que se presume enquanto apropriação ativa do sujeito que recebe a transmissão.

A assertiva do autor de que o método de ensino se dá no "[...] confronto entre a experiência e a explicação do professor" (LIBÂNEO, 1985, p. 40, destaque dos autores) deixa evidente uma perspectiva didática fundada no método explicativo-ilustrativo, considerado uma das vias metodológicas mais comumente empregadas na didática da época, com foco na atividade prática do professor. Entretanto, o aspecto mais sobressaliente é a importância que J. C. Libâneo concede ao conteúdo como componente 
fundamental do processo educacional, do qual deriva todo o resto, inclusive os métodos.

A difusão de conteúdos é a tarefa primordial. [...] A valorização da escola como instrumento de apropriação do saber é o melhor serviço que se presta aos interesses populares, já que a própria escola pode contribuir para eliminar a seletividade social e tornála democrática. [...] Assim, a condição para que a escola sirva aos interesses populares é garantir a todos um bom ensino, isto é, $\underline{\text { a }}$ apropriação dos conteúdos escolares básicos que tenham ressonância na vida dos alunos (LIBÂNEO, 1985, p. 41, destaques dos autores).

O destaque que os conteúdos têm no interior da concepção filosófica da didática de J. C. Libâneo é a espinha dorsal que conecta esse momento de seu pensamento, ao pensamento didático nas perspectivas histórico-cultural e desenvolvimental, bem como com o ideário pedagógico marxista brasileiro representado pelas Pedagogia Histórico-Crítica e Pedagogia Crítico-Social dos Conteúdos.

\section{Considerações Finais}

A gênese e formação do pensamento didático desenvolvimental de J. C. Libâneo podem ser localizadas, como o presente texto procurou demonstrar, nos pressupostos fundamentais da filosofia marxista e da psicologia histórico-cultural; tendo por base o conteúdo como elemento essencial no processo de uma educação autotransformadora e desalienante.

O presente estudo constatou que tanto a obra quanto o pensamento do autor são exemplos genuínos de uma capacidade insuperável de engajamento político, intelectual, acadêmico e social, no campo da didática. Sua produção intelectual é referência na maior parte dos cursos de 
graduação e pós-graduação em educação, sobretudo, nas áreas de didática, formação de professores e gestão escolar.

A trajetória do pensamento do autor demonstra que entre suas contribuições teóricas mais importantes sobressai, a partir do ano de 2002 , uma aproximação com as teses psicológicas histórico-culturais, posteriormente, intensificadas na análise dos princípios do Ensino Desenvolvimental, do conteúdo da Atividade de Estudo e do método do abstrato ao concreto como forma de desenvolvimento do pensamento teórico, com foco nos aportes do sistema Elkonin-Davidov-Repkin e, mais particularmente, do grupo de Moscou representado por V. V. Davidov, a quem tem estudado nos últimos quase vinte anos.

A pesquisa sobre a vida e obra de V. V. Davidov (cf. LIBÂNEO; FREITAS, 2013; 2019; entre outros) direcionou o percurso investigativo de J. C. Libâneo no sentido de um sistemático processo de aprofundamento da Teoria do Ensino Desenvolvimental, da qual a didática constitui uma de suas teorias auxiliares mais importantes, representada por esse psicólogo russo que, sem lugar a dúvida, é seu representante mais produtivo e consistente. Nessa área, J. C. Libâneo tornou-se uma referência que extrapola os limites geográficos brasileiros, nos quais marca o campo da didática no final do século XX e começo do XXI.

\section{Referências}

BORMEY, María Teresa Vila; LEÓN, Rafael Plá; RODRÍGUEZ, Pascual Valdés. Evald Vasílievich Iliénkov: una mirada filosófica a la psicología e a la pedagogía. In: PUENTES, Roberto Valdés; LONGAREZI, Andréa Maturano (Orgs.). Ensino desenvolvimental: vida, pensamento e obra dos principais representantes russos. Livro III. Uberlândia: Edufu; Jundiaí: Paco Editorial, 2019, p. 107-144.

DANILOV, M. A. El proceso de enseñanza en la escuela. La Habana: Editorial de libros para la educación, 1978.

DANILOV, M. A.; SKATKIN, M. N. Didáctica de la escuela media. La Habana: Editorial Pueblo e Educación, 1978.

DAVIDOV, Vasily Vasilyevich. Problems of developmental teaching. The experience 
of theoretical and experimental psychological research. Soviet Education, New York, 1988.

DAVIDOV V. V., MÁRKOVA, A. K. La concepción de la actividad de estudio en los escolares. In: Shuare, M (ed.) La psicología evolutiva y pedagógica en la URSS: Antología, Editorial Progreso, Moscú, 1987.

FREITAS, Raquel A. M. DA M.; LIBÂNEO, José C. Didática desenvolvimental e políticas para a escola no Brasil. In: PUENTES, Roberto V.; LONGAREZI, Andréa M. Dossiê Didática desenvolvimental: diferentes concepções histórico-culturais. LINHAS CRÍTICAS (ONLINE), v. 24, p. 367-387, 2019.

KLINGBERG, L. Introducción a la didáctica general. La Habana: Editorial Pueblo y Educación, 1978.

LEONTIEV, Alexei N. O Homem e a Cultura. In: VV.AA. O papel da cultura nas ciências sociais. Porto Alegre: Ed. Villa Martha, 1980.

LIBÂNEO, José Carlos. Didática e prática histórico-social - uma introdução aos fundamentos da educação. Revista Ande, São Paulo, n. 8, 1984.

LIBÂNEO, José Carlos. Psicologia educacional: uma avaliação crítica. In: LANE, Silvia T. M.; CODO, Wanderley (Orgs.). Psicologia social - O homem em movimento. São Paulo: Editora brasiliense, 1984, p. 154-180.

LIBÂNEO, José Carlos. Democratização da escola pública: pedagogia crítico-social dos conteúdos. 14ª edição. São Paulo: Edições Loyola, 1985[1996].

LIBÂNEO, José C. Os conteúdos escolares e sua dimensão crítico-social. Revista da Ande, GOIÂNIA-GO, v. 11, p. 5-13, 1986.

LIBÂNEO, José Carlos. A didática e as tendências pedagógicas. Idéia, São Paulo, p. 28-38, 1991.

LIBÂNEO, José Carlos. Didática. São Paulo. Cortez, 1990[2002].

LIBÂNEO, José C. Organização e gestão da escola. 1a. ed. Goiânia - GO: Alternativa, 2000a. 259p.

LIBÂNEO, José C. Organização e gestão da escola: teoria e prática. Goiânia: Edição do Autor, 2000b. 177p.

LIBÂNEO, José Carlos. Panorama do ensino da didática, das metodologias específicas e das disciplinas conexas nos cursos de Pedagogia: repercussões na qualidade da formação profissional. LONGAREZI, Andréa Maturano; PUENTES, Roberto Valdés (Orgs.). Panorama de didática: ensino, prática e pesquisa. Campinas: Papirus, 2001, p. 11-50.

LIBÂNEO, José C. Pedagogia e pedagogos, para quê? 4a. ed. São Paulo: Cortez Editora, 2001a. 200p. 
LIBÂNEO, José C. Adeus professor, adeus professora? Novas exigências educacionais e profissão docente. 5a. ed. São Paulo: Cortez Editora, 2001b. 103p.

LIBÂNEO, José Carlos. A constituição do objeto da Didática: contribuição da ciência da educação. Texto publicado nos Anais do VII ENDIPE. Encontro Nacional de Didática e Prática de Ensino, Goiânia, 1994, p.65-78. In: LIBÂNEO, José Carlos. Didática: velhos e novos tempos. Goiânia: Edição do autor, maio de 2002, p. 8-18. Disponível em http://files.anajatubaateniense-blogspotcom.webnode.com/200000260-8102181f63/Jose\%20Carlos\%20Libaneo\%20\%20Livro\%20Didatica\%20Lib\%C3\%A2neo.pdf, acesso em 07/10/2019.

LIBÂNEO, José Carlos. O modo de pensar didático e a metodologia do ensino da Didática (a relação objetivo-conteúdo-método na Didática Crítico-social (1991[2002]). VI Encontro Nacional de Didática e Prática de Ensino, Porto Alegre, de 2 a 6.12.1991. In: LIBÂNEO, José Carlos. Didática: velhos e novos tempos. Goiânia: Edição do autor, maio de 2002, p. 81-85. Disponível em http://files.anajatubaateniense-blogspot-com.webnode.com/2000002608102181f63/Jose\%20Carlos\%20Libaneo\%20\%20Livro\%20Didatica\%20Lib\%C3\%A2neo.pdf, acesso em 07/10/2019.

LIBÂNEO, José C. A didática e a aprendizagem do pensar e do aprender: a teoria histórico-cultural da atividade e a contribuição de Vasili Davydov. Revista Brasileira de Educação, Rio de Janeiro, v. 27, n.27, p. 5-24, 2004a.

LIBÂNEO, José C. A aprendizagem escolar e a formação de professores na perspectiva da psicologia histórico-cultural e da teoria da atividade. Educar em Revista, Curitiba (PR), n.24, p. 113-147, 2004b.

LIBÂNEO, José C. Memorial: trajetória intelectual e profissional (anos 1995-1991). Goiânia: Faculdade de Educação/Universidade Federal de Goiás, 2006.

LIBÂNEO, José Carlos. Didática e epistemologia: para além do embate entre a didática e as didáticas específicas. In: VEIGA, Ilma P. Alencastro; e D'ÁVILA, Cristina (Orgs.). Profissão docente: novos sentidos, novas perspectivas. Campinas (SP): Papirus Editora, 2008b.

LIBÂNEO, José C. O declínio da escola pública brasileira: apontamentos para um estudo crítico. In: LOMBARDI, José C.; SAVIANI, Dermeval. (Org.). História, educação e transformação. 1ed. Campinas SP: Autores Associados, 2011, v. 1, p. 157-185.

LIBÂNEO, José Carlos. Políticas educacionais neoliberais e escola pública: uma qualidade restrita e restritiva de educação. In: LIBÂNEO, José Carlos; FREITAS, Raquel Aparecida Marra da Madeira (Orgs.). Políticas educacionais neoliberais e escola pública: uma qualidade restrita de educação escolar. - $1^{\mathrm{a}}$ ed. - Goiânia: Editora Espaço Acadêmico, 2018, P. 44-87.

LIBÂNEO, José Carlos. Depoimento [mensagem pessoal]. Mensagem recebida por <andrea.longarezi@gmail.com.br> em 23 abril 2020. 
LIBÂNEO, José C.; FREITAS, R. A. M. M. Vygotsky, Leontiev, Davidov contribuições da teoria histórico-cultural para a didática. In: SILVA, C. C.; SUANNO, M. V. R. (Org.). Didática e interfaces. 1ed. Rio de Janeiro/Goiânia: Descubra, 2007, p. 39-60.

LIBÂNEO, José Carlos; FREITAS, Raquel A. Marra da Madeira. Vasily Vasilyevich Davydov: a escola e a formação do pensamento teórico-científico. In: LONGAREZI, Andréa Maturano; PUENTES, Roberto Valdés (Orgs.). Ensino desenvolvimental: vida, pensamento e obra dos principais representantes russos. Uberlândia: Edufu, 2013, p. 315-350.

LIBÂNEO, José Carlos; FREITAS, Raquel Aparecida Marra da Madeira. A pesquisa: repercussões de políticas educacionais na escola e na sala de aula. In: LIBÂNEO, José Carlos; FREITAS, Raquel Aparecida Marra da Madeira (Orgs.). Políticas educacionais neoliberais e escola pública: uma qualidade restrita de educação escolar. - $1^{\text {a }}$ ed. - Goiânia: Editora Espaço Acadêmico, 2018, p. 23-44.

LIBÂNEO, José Carlos; FREITAS, Raquel Aparecida Marra da Madeira. Abstração, generalização e formação de conceitos no processo de ensino e aprendizagem. In: PUENTES, Roberto Valdés; LONGAREZI, Andréa Maturano (Orgs.). Ensino desenvolvimental: sistema Elkonin-Davidov-Repkin. Campinas: Mercado de Letras; Uberlândia: Edufu, 2019, p. 213-240.

LONGAREZI, Andréa M. Para uma Didática Desenvolvimental e dialética no contexto de escolas públicas brasileiras. Obutchénie: Revista De Didática E Psicologia Pedagógica, vol. 1, n. 1, 2017, p. 187-230.

LONGAREZI, Andréa M. Prefácio. PUENTES, R. V.; CARDOSO, C. G. C.; AMORIM, P. A. P. (Orgs.). Teoria da atividade de estudo: contribuições de D. B. Elkonin, V. V. Davidov e V. V. Repkin. 1. ed. Curitiba: CRV, 2019a.

LONGAREZI, Andréa M. Significado e sentido na atividade de estudo: uma problematização dos motivos na estrutura da atividade. MILLER, Stela; GUADALUPE, Sueli de 1. M. KOHLER, Érika C. (Org.) Significado e sentido na educação para a humanização. Marília: Oficina Universitária; São Paulo: Cultura Acadêmica, 2019b, p. 257-290.

LONGAREZI, Andréa M. Teoria do experimento formativo. In: PUENTES, Roberto V.; LONGAREZI, Andréa M. (Orgs.) Ensino Desenvolvimental. Sistema ElkoninDavidov-Repkin. Campinas: Mercado de Letras - Uberlândia: Edufu, 2019c.

LONGAREZI, Andréa M. Didática Desenvolvimental: um olhar para sua gênese na tradição da teoria histórico-cultural e possíveis desdobramentos para a realidade brasileira. In: Anais do IV Evento do método e metodologia em pesquisa na abordagem do materialismo histórico-dialético e da psicologia histórico-cultural. Maringá: UEM, 2019d. 
LONGAREZI, Andréa M.; DIAS DE SOUSA, Waleska D. D. de. Unidades possíveis para uma obutchénie dialética e desenvolvedora. Linhas Críticas, v. 24, 2019, $p$. p.453-474.

LONGAREZI, Andréa M; SILVA, Diva S. Formação de professores e sistemas didáticos na perspectiva histórico-cultural da atividade: panorama históricoconceitual. Apresentação. Obutchénie. Revista de Didática e Psicologia Pedagógica. Uberlândia, v. 2, n.3, p. 571-590, 2018. Disponível em:< http://www.seer.ufu.br/index.php/Obutchenie/article/view/47433/25643> Acesso em: 21.03.2019.

LONGAREZI, Andréa M.; PEDRO, Luciana G.; PERINI, Jacqueline F. Teoria da atividade e formação de professores: algumas aproximações. Ensino em Re-vista Uberlândia, v. 18, n.2, p. 389-400, 2011. Disponível em: < http://www.seer.ufu.br/index.php/emrevista/article/view/13859>. Acesso em julho de 2020.

LONGAREZI, Andréa M.; PUENTES, Roberto V. A ascensão do pensamento didático desenvolvimental na obra de José Carlos Libâneo (1976-2020). In: SUANNO, Marilza Vanessa R.; CHAVES, Sandramara M.; LIMONTA, Sandra V. Educação como prática social - Homenagem ao Prof. Dr. José Carlos Libâneo, 2020.

PUENTES, Roberto Valdés. Didática desenvolvimental da atividade: o sistema Elkonin-Davidov (1958-2015). Obutchénie, Uberlândia, v. 1, n. 1, p. 20-58, 2017.

PUENTES, Roberto Valdés. Uma nova abordagem da teoria da aprendizagem desenvolvimental. In: PUENTES, Roberto Valdés; CARDOSO, Cecília Garcia Coelho; AMORIM, Paula Alves Prudente (Orgs.). Teoria da atividade de estudo: contribuições de D. B. Elkonin, V. V. Davidov e V. V. Repkin. Curitiba: CRV; Uberlândia: Edufu, 2019a, p. 31-53.

PUENTES, R. V. O sistema Elkonin-Davidov-Repkin no contexto da didática desenvolvimental da atividade (1958-2015). In: Roberto Valdés Puentes; Cecília Garcia Coelho Cardoso; Paula Alves Prudente Amorim. (Org.). Teoria da atividade de estudo: contribuições de D. B. Elkonin, V. V. Davidov e V. V. Repkin. 1ed.Curitiba: CRV, 2019b, v. 10, p. 53-80.

PUENTES, R. V. A noção de sujeito na concepção da Aprendizagem Desenvolvimental. Obutchénie, Uberlândia, v.3. n.a p. 58-87, 2019c.

PUENTES, Roberto Valdés; LONGAREZI, Andréa Maturano. A didática desenvolvimental: seu campo conceitual na tradição da psicologia histórico-cultural da atividade. In: LONGAREZI, A. M.; PUENTES, R. V. (Orgs.). Fundamentos psicológicos e didáticos do ensino desenvolvimental. Uberlândia: Edufu, 2017a, p.187-224.

PUENTES, R. V.; LONGAREZI, A. M. Didática desenvolvimental: sessenta anos de tradição teórica, epistemológica e metodológica. Obutchénie, Uberlândia, v. 1, p. 9$19,2017 \mathrm{~b}$. 
PUENTES, R. V.; LONGAREZI, A. M. Uma introdução à Didática Desenvolvimental soviética e suas diferentes interpretações no âmbito Latinoamericano (Brasil, Cuba e México). Linhas Críticas (ONLINE), Brasília, v. 24, p. 278-283, 2018.

PUENTES, Roberto V.; LONGAREZI, Andréa M. (Orgs.). Ensino Desenvolvimental. Sistema Elkonin-Davidov-Repkin. Campinas: Mercado de Letras - Uberlândia: Edufu, 2019.

PUENTES, R. V.; AMORIM, P. A. P.; CARDOSO, C. G. C. Didática desenvolvimental da atividade: contribuições de V. V. Repkin ao sistema ElkoninDavidov. Ensino em Revista, Uberlândia, v. 24, p. 130-150, 2017. DOI: https://doi.org/10.14393/ER-v24n1a2017-12.

REPKIN, Vladimir Vladimirovich; REPKINA, Natalya V. Modelo teórico da aprendizagem desenvolvimental. In: PUENTES, Roberto Valdés; LONGAREZI, Andréa Maturano (Orgs.). Ensino desenvolvimental: Sistema Elkonin-DavidovRepkin. Campinas: Mercado de Letras; Uberlândia: Edufu, 2019, p. 27-75.

REVYAKINA, V. I.; LOBANOV, V. V., KULIKOV, S. B. The Developmental Education and its Relevance to the Russian Innovative Pedagogy. Obutchénie, Uberlândia. v. 1, n. 1, p. 59-69, 2017.

VIGOTSKY, Lev Semenovich. A formação social da mente. São Paulo: Martins Fontes, 1984.

Recebido em maio de 2020. Aprovado em agosto de 2020. 